\title{
Negotiating Climate Resilience in Nepal
}

\author{
Jessica Ayers, Nanki Kaur and Simon Anderson*
}

\begin{abstract}
One of the key drivers of the global political economy of climate change is the evolving financial architecture; yet there is little research into how this plays out at the national level. How will the new ideas and ideologies be received and interpreted in national policymaking arenas? What does this mean for how power, processes and resources are negotiated and institutionalised? This article addresses these questions through a case study analysis of the Pilot Program for Climate Resilience (PPCR) in Nepal. We examine how the global objectives of the PPCR are being interpreted and re-conceptualised by different actors; and how this conceptualisation is influenced by, and reinforces or challenges, existing political ideologies and interests. We suggest that attention to these dynamics could help resolve some emerging tensions as the PPCR moves forwards towards implementation.
\end{abstract}

\begin{abstract}
1 Introduction
The global climate change governance architecture provides a space within which climate change problems and responses are conceptualised and negotiated. However, such negotiations are not based on rational debate over normative concepts within neutral policymaking arenas. Instead, political economy analysis shows how negotiations over climate change policy problems are driven by power politics between different actors that serve to promote or sideline different positions (see Tanner and Allouche, this IDS Bulletin). Furthermore, the positions that are negotiated are not necessarily 'objective'; the conceptualisation of policy problems and solutions is also highly politicised and tied to different values and political ideologies (Clapp and Dauvergne 2005). This article responds to calls to understand climate change through a political economy framework that takes into account the political and ideological processes embedded in the global climate change governance architecture (see Tanner and Allouche, this IDS Bulletin).
\end{abstract}

The evolving financial frameworks for managing climate change provide a key site through which the global political economy of climate change plays out. There is an increasing proliferation of climate change funds and mechanisms for generating and channelling resources, each bringing to the arena new resources, actors and institutional ideologies. For example, until recently, all significant funding for climate change adaptation fell under the remit of the United Nations Framework Convention on Climate Change (UNFCGC). However, consensus over the inadequacy of UNFCCG funds to meet climate change response needs in vulnerable developing countries (Chandani and Siegele 2010; Mitchell et al. 2008) has given rise to the World Bank approved Climate Investment Funds (CIFs). The CIFs are a collaborative effort among the multilateral development banks (MDBs) intended to 'bridge the financing gap' for supporting developing countries in responding to climate change (www.climateinvestmentfunds.org). The CIFs are larger than all of the existing funds under the UNFCCG process. The CIFs therefore both reflect and are likely to catalyse significant changes in the global political dynamics and incentive structures of climate change response measures (Seballos and Kreft, this IDS Bulletin).

This changing international landscape of climate finance has an influence on the national-level political economy context of both climate change and development decision-making. Unprecedented environmental investments are generating new incentives for national policymakers and implementing agencies; new governance 
mechanisms are being shaped by different actors, ideas and interests to manage the disbursal of funds and implementation of action; and these mechanisms are providing new arenas to re-negotiate and re-conceptualise both global and national development and climate change approaches. Yet to date, there is relatively little research into how these changes to global level political and financial dynamics might play out at the national level. What do these changes in the international political economy of climate change mean for the dynamics of climate change policy processes at the national level? How will the new ideas and ideologies around climate change adaptation be received and interpreted in national policymaking arenas? What does this mean for how power, processes and resources are negotiated and institutionalised?

This article addresses this research gap through a detailed case study analysis of one of the CIFs, the Pilot Program for Climate Resilience (PPCR), in Nepal. We begin by reviewing the objectives of the PPCR, including the assumptions and ideologies underpinning these objectives. Second, we assess how these objectives are being interpreted and reconceptualised by different actors at the national scale in Nepal; and how this conceptualisation is influenced by, and reinforces or challenges, existing political ideologies and interests. Third, we consider the institutional implications of these different conceptualisations, including conflicting approaches to power and resource allocation in the design and implementation of the PPCR. Finally, we suggest that greater attention to these political economy dynamics of the PPCR process could help resolve some of the tensions emerging between different actors and divergent interests in the PPCR process as it moves forwards towards implementation.

The findings presented in this article are based on case study data on the PPCR process in Nepal collected and analysed between July and December 2010. Methods of data collection included an initial stakeholder and institutional analysis conducted at the outset of the study and updated throughout the study period; key informant interviews (semi-structured and openended) with stakeholders identified through the stakeholder mapping exercise, including from government, donor agencies, MDBs and civil society; and document analysis of formal and informal PPCR and climate change planning documentation generated throughout the PPCR process from its inception in May 2009 through to the outputs of the most recent mission in November 2010.

\section{The PPCR: objectives and assumptions}

The PPCR is seen as the CIF 'adaptation fund' indeed it was initially entitled the 'Adaptation Pilot Fund' but the World Bank changed this title in response to criticisms that it would compete with the Adaptation Fund under the UNFCGC (Müller 2008). The PPCR has the overall objective to 'pilot and demonstrate ways to integrate climate risk and resilience into core development planning, while complementing other ongoing activities' (CIF 2008: 2). The PPCR aims to achieve this by,

... providing incentives for scaled-up action and transformational change in integrating consideration of climate resilience in national development planning consistent with poverty reduction and sustainable development goals. (CIF 2008: 2)

In reframing itself as a fund for building 'climate resilience' rather than 'adaptation', and by placing emphasis on integrating resilience into national development planning, the development of the PPCR marked a shift in thinking for adaptation support under the global climate change governance architecture. Conventional support for adaptation under the UNFCGC has been criticised for taking a narrow interpretation of adaptation as a response to specific climate change impacts (Burton et al. 2002; Schipper 2006). This approach has been branded an 'impacts-first' approach to defining climate risks (Burton et al. 2002), which has resulted in what Klein defines as 'technology-based' adaptation interventions such as dams, early-warning systems, seeds and irrigation schemes based on specific knowledge of future climate conditions (Klein 2008). This is in line with what Bernstein (2002: 4) describes as a 'liberal environmental' ideology around environmental governance, which promotes a technical understanding of environmental and sustainability problems, and promotes solutions that are compatible with economic growth.

However, this technocratic and isolated approach to supporting adaptation has been heavily 
criticised for failing to address the contextual factors related to development that determine vulnerability to climate change impacts; that enable or disable resilience to climate change impacts (Schipper 2007). Instead, such critics have advocated for a more integrated approach to supporting adaptation in developing countries, that sees adaptation 'mainstreamed' into development planning (Reid et al. 2003; Klein 2008).

Similarly, the goal of 'transformational change' is an innovative step towards reframing what is meant by adaptation to climate change, beyond 'building resilience'. 'Resilience' requires building adaptive capacity - the more resilient a unit, the greater its capacity to adapt, and so the less vulnerable it is to climate and other hazards. But resilience is also only a first step towards adaptation in a situation where vulnerability is determined by a development deficit situation. This is because 'resilience' implies returning a system to its original state following disturbance (Dodman et al. 2009). This interpretation of resilience stems from its use in both engineering and ecology, and is echoed by the Intergovernmental Panel on Climate Change (IPCC) as applied to climate change: 'The ability of a social or ecological system to absorb disturbances while retaining the same basic structure and ways of functioning' (IPCG 2007: 880; own emphasis).

'Transformation' on the other hand, although never explicitly defined by the PPCR documentation, suggests changes to the structural constraints that impede adaptation, challenging the systems that drive vulnerability (Pelling 2010). This could be taken as incompatible with 'resilience', which does not require changes to guiding assumptions or established frameworks. However, Pelling (2010) suggests that resilience and transformational change are in fact co-dependent: higher-order transformational change can create the conditions for systems to be resilient, and a lack of resilience at lower orders stifles the conditions necessary for transformational change.

By striving for both 'resilience' and also 'transformational change', the PPCR seemingly takes significant steps towards moving beyond a narrowly focused approach to adaptation, towards understanding and focusing on the interactions between climate change vulnerability and development. Such indications have led observers such as Ayers and Huq (2009) to optimistically suggest that the arrival of the PPCR signified a real opportunity for development assistance to address underlying factors of vulnerability that are overlooked by a Convention-based approach. The authors state:

[The establishment of the PPGR] does point to progress in understanding... 'climate-resilient development' - rather than specific and additional climate-change adaptation... new development funds relevant to climate-change adaptation should be used to fund what the UNFCGC cannot; namely, broader resilience building, necessary for 'additional' adaptation to be successful. (Ayers and Huq 2009: 682)

However, the selection process of pilot countries to the PPCR suggest that a technocratic and 'impacts-based' ideology remains pervasive in the institutions managing PPCR. For instance, the selection process for pilot countries involved first screening developing countries in line with their exposure to climate change impacts (based on predefined climate change impacts selected by an external expert committee); and then those regions or countries selected as 'climate change hotspots' being screened for 'vulnerability' based on a range of poverty and development-related indicators. Nepal, for example, was selected as a PPCR pilot country, based on its status as a 'vulnerable mountain environment... [with] potentially serious implications associated with rapid glacial melt', as well as having low 'adaptive capacity' based on a low score on Human Development Indicators (CIF 2009: 20). This approach gives primacy to climate change impacts over development indicators in defining vulnerability, and also assesses the two separately, rather than assessing the interactions between them in each country. This illustrates the political nature of defining vulnerability even where scientific criteria are used (see Klein and Möhner, this IDS Bulletin). The political alterations to the selection process after this assessment further underline this assertion (see Seballos and Kreft, this IDS Bulletin).

The remainder of this article will consider the extent to which the PPGR in Nepal has indeed refocused adaptation support towards integrated, development-based resilience building and 


\begin{tabular}{lll}
\hline Table 1 Different perceptions of climate resilience and adaptation & \\
\hline Stakeholder group & Interpretation of climate resilience & Adaptation \\
\hline MOE & - Synonymous with adaptation & - Long term and strategic \\
& - Long term and strategic & - Programmatic and integrated \\
& - Programmatic and integrated & - Addresses underlying vulnerability to climate \\
& - Addresses underlying vulnerability to & variability and climate change \\
& climate variability and climate change & \\
& - Long term and strategic & - Urgent and immediate \\
& - Mainstreamed & - Short term \\
MDB/Consultants & 'Climate proofing' & Projectised \\
& 'Climate risk management & - Response to current climatic variability \\
& - Response to future climate change & - Does not adequately address longer-term \\
& 'An additional need in light of new & climate resilience \\
& climate risks & \\
& The same as adaptation, i.e.: & - Long term and strategic \\
& - Long term and strategic & - Programmatic and integrated \\
& - Programmatic and integrated & - Addresses underlying vulnerability to climate \\
& - Addresses underlying vulnerability to & variability and climate change \\
& climate variability and climate change & \\
Donor & & \\
\hline Source Interview data. & &
\end{tabular}

'transformational change'; or how far a technocratic and top-down ideology of how to 'do' adaptation has filtered down to the country level and influenced the way in which resilience and adaptation is being interpreted under the PPCR in Nepal.

\section{PPCR planning process in Nepal: negotiating resilience and transformational change at the national level}

Nepal's engagement with the PPGR began with the acceptance of the offer for participation in the PPCR by the Ministry of Environment (MOE), the national focal point for the PPCR, on behalf of the Government of Nepal on 13 May 2009. The preparation of the PPCR in Nepal is being facilitated by the World Bank and the Asian Development Bank (ADB). To date, the MDBs have fielded two Joint Missions to Nepal (in September 2009 and November 2010), and a small team of national and international consultants has been seconded to the MOE to work with the government on the development of the first phase of PPCR preparation, the development of a Strategic Program for Climate Resilience (SPCR). Through a process of fieldlevel vulnerability assessments, detailed consultations and a review of climate and development policy documents, the SPGR consulting team, MDBs and MOE have designed and agreed upon four draft components of the SPCR (ADB et al. 2010):

1 Building Climate Resilient Watershed and Water Resources in Mountain Eco-regions;

2 Building Resilience to Climate-related Extreme Events;

3 Mainstreaming Climate Change Risk Management in Development;

4 Building Climate Resilient Communities through Private Sector Participation.

The PPCR process in Nepal has opened up many new (and some old) issues for negotiation, and created new sites for these issues to be contested. This section reviews some of the key issues that were contested during the PPCR process, and considers how some of these points of tension can be traced back to conflicting interpretations of the universal remit of the PPCR at the national level between different actors with different interests.

\subsection{Achieving 'climate resilience'}

Resilience has been defined in different ways by different stakeholder groups (see Table 1). Specifically, the MDBs interpreted 'climate resilience' as distinct from adaptation; while the MOE did not make this distinction. These conflicting definitions resulted in some confusion over the relationship between the PPCR and 
another climate change planning process that was running simultaneously in Nepal: The development of the National Adaptation Programme of Action (NAPA). All stakeholders generally agreed that NAPA was 'adaptation planning' and the PPCR was 'climate resilience', but the extent to which the two should be focused on different objectives has been a source of tension during PPCR development. The PPCR guidelines suggest that the PPCR should 'build on NAPAs'. From the perspective of the MOE, this means that the adaptation planning undertaken during NAPA could and should be eligible for funding under the PPCR, because NAPA priorities should also 'build resilience' (interview with MOE, September 2010).

However, from the perspective of the MDBs, 'NAPAs are for adaptation planning, the PPCR is to build climate resilience' (interview with MDB consultants, September 2010) and 'adaptation' and 'resilience' are not the same thing. From the perspectives of the MDBs and PPCR consulting team, 'adaptation' as defined under the NAPA refers to 'urgent and immediate adaptation needs', and 'projectised approaches', where as 'climate resilience' is 'long term and strategic', 'mainstreamed' and 'programmatic' (interviews with MDBs and consultants, September 2010). 'Mainstreamed' is taken by this group of stakeholders to refer to 'climate proofing', and applied to ensuring infrastructure and in some cases, policy was robust under future climate change scenarios. From this perspective, the focus of 'climate proofing' is adding to existing measures to make them more resilient to a future climate change - rather than, for example, making existing measures more robust to a range of development and climate risks.

This interpretation of climate resilience echoes a globalised technocratic discourse on adaptation, described above, that takes climate impacts as the starting point for adaptation planning, rather than the underlying factors that drive or undermine resilience. This has resulted in a strong emphasis under the PPCR of climate change trend analysis and climate information in the analysis of 'adaptive capacity'. The focus is on the capacity of communities, sectors or agencies to be more resilient to future climate changes, but not more resilient in general. This is well exemplified by the way in which 'progress' against 'adaptive capacity' will be monitored and evaluated under the SPCR. The SPGR project document states that:
In order to establish a benchmark against which SPCR interventions will be measured, an adaptive capacity assessment will also be done within identified resilient communities for the following events - flood, drought, heat, extreme event, climate variability.

(SPCR Team 2010)

This assumes that 'resiliency' can be controlled, and is a factor of the capacity to respond to these five climate-change related impacts. This approach does not allow for the myriad of factors that could constrain or enable resiliency or a broader definition of adaptive capacity. 'Adaptive capacity' under the PPCR refers largely to 'climate risk management capacity' (SPCR Team 2010).

The MOE and to some extent donors however, interpreted adaptation under Nepal's NAPA as also long term and strategic, rather than projectised. This is explicit in the way in which co-financing was mobilised in order to ensure a more 'programmatic and long term approach' to NAPA preparation (MOE 2010). From this perspective, using a distinction between 'adaptation' and 'resilience' as a reason why the PPCR cannot be used to finance NAPA caused a lot of confusion for the government and donor stakeholders; as remarked by one donor, 'it's splitting hairs. What's the point of adaptation if it is not also long term and strategic?' The government also felt that the MDB definition of adaptation under the NAPA undermined the significant effort that had gone into moving away from projectised perceptions of adaptation. As noted by one member of MOE:

We have learned a lot from other countries' NAPAs. We are really learning and using this learning in the Nepal NAPA, to make adaptation part of a longerterm strategy; this should be recognised.

The tension over the relationship between the NAPA and the PPCR has been somewhat managed by the way in which the SPCR development has explicitly built on NAPA in its development. For example, through engagement of NAPA Thematic Working Group members in the PPCR preparation process; the repeated referencing of the NAPA throughout the PPCR inception documents, and the use of NAPAgenerated information as 'background' to the SPCR processes. 


\begin{tabular}{|c|c|}
\hline Stakeholder group & Transformational change \\
\hline MOE & $\begin{array}{l}\text { Beyond consultants and technical assistance - full capacity within government to manage } \\
\text { climate change } \\
\text { Adaptive capacity enhanced at the local level } \\
\text { Adaptive capacity no longer constrained by poverty }\end{array}$ \\
\hline MDB/Consultants & $\begin{array}{l}\text { Moving beyond 'business as usual' } \\
\text { Systems, processes and procedures are climate proofed } \\
\text { Over and above development - influence the way development decisions are made in light of } \\
\text { climate change risks }\end{array}$ \\
\hline Donor & $\begin{array}{l}\text { Transformation of national systems for longer-term 'adaptive management' } \\
\text { Focus on governance } \\
\text { Moving away from a dependence on donor technical assistance towards governments being } \\
\text { able to do this themselves }\end{array}$ \\
\hline
\end{tabular}

However, these different perceptions around what constitutes resilience are reflective of higher order assumptions and vested interests that are embedded in the approaches taken by different stakeholders. For example, the Government of Nepal was one of the last countries to develop its NAPA and so had seen the challenges faced by other countries in securing NAPA funding. By interpreting 'climate resilience' and 'adaptation' as the same, this would justify PPCR funding NAPArelated activities thereby overcoming the funding challenge. Further, this would demonstrate to the international community (to which the MOE is accountable at the meetings of the UNFCCG) that Nepal has used the delays in the NAPA process constructively, learning from criticisms of other NAPAs that had taken a projectised approach to adaptation planning, and also by proactively seeking new avenues for funding its NAPA.

The donors - specifically the UK Department for International Development (DFID) - also have particular interests in taking 'adaptation' and 'resilience' as the same. DFID had put significant co-financing into the development of the NAPA and are also major donors to the PPCR. This means it is in DFID's interests to see the two processes aligned to maximise the effectiveness of investments in both; but also because the co-finance for the NAPA was intended to try and ensure the NAPA in Nepal took a more strategic approach, and this investment is more justified if the NAPA is interpreted as also building resilience beyond projectised adaptation.
The MDBs on the other hand are responding to the international PPCR agenda as set by the World Bank. The guidelines for the PPCR suggest that PPCRs should build on NAPAs, but in all other PPCR countries the NAPAs had already been completed, so this process was more straightforward - PPCRs should move beyond what had already been done. In Nepal, because the two processes were going on at the same time, these guidelines needed to be reinterpreted. Yet, the agenda driven from above, and the 'mission style' approach to NAPA development, did not leave much scope for the MDBs to get a more comprehensive understanding of the specific circumstances of the NAPA in Nepal.

\subsection{Transformative change}

Like 'resilience', the 'transformational change' remit of the PPCR has not been consistently defined by different stakeholders in the PPCR process in Nepal, and has been used to justify a number of different and not necessarily consistent approaches (see Table 2).

As with 'resilience', the different interpretations of 'transformational change' all reflect different interests and values of the stakeholders that hold them. From the perspective of the MOE, transformational change means the capacity to adapt at all scales, from national and sectoral governance systems right down to the local level. The government has put a great deal of emphasis on enabling adaptive capacity at the local level, for example the government requires all significant climate investments to demonstrate that 80 per 
cent of funds for climate finance go on project implementation and not on higher level technical assistance (the government has insisted that this is the case under the NAPA implementation; DFID/EU adaptation investments; and the PCPR). The MOE argue that transformation is not all about building technical capacity at the national level, and that consulting services are not transformational. As noted by one MOE official:

Stop trying to build my capacity!... We need to deliver... When the vulnerable people can adapt, that is when transformation has happened.

(Interview with MOE, October 2010)

Such an approach is consistent with the accountability incentives for the MOE, to both the government and the people of Nepal (and frequently held to account by a vibrant civil society and media). Focusing on using adaptation finance for delivery and not just capacity building generates visible outcomes from climate change investments to help the government justify how the money is being used.

From the MDB perspective, 'transformational change' means providing access to knowledge and resources to be able to 'climate proof' development investments. Climate change is bringing about new risks, so 'business as usual' development planning is no longer enough and planning systems need to be 'transformed' in order to be able to take account of these risks. The Aide Memoire from the most recent PPCR mission operationalises this perception in relation to SPCR planning in Nepal, as follows:

The traditional 'business as usual' approach to development planning in Nepal is not designed to cope with current climate risks. National efforts to build climate resiliency suffers from a lack of high quality standardised data to inform early warning systems and insufficient technical capabilities to apply appropriate climate change risk management tools. (ADB et al. 2010)

Thus, transformational change from this perspective is dependent on data and technical capacity in government planning systems.

The donor perspective here represents the DFID country office. As noted, DFID is one of the main donors to the PPCR in Nepal, and also to the two other major climate change investment programmes - the NAPA and a DFID/EU work programme. As such, DFID has a vested interest in seeing the PPCR well coordinated, with the other climate change investment programmes; but this also perhaps encourages a 'bigger picture' perspective beyond the remit of the PPCR towards how to enable effective climate change resilience more generally, and creating an agenda behind which all investments can align, and a framework that would support all investments. A strong governance framework that enables access to financial, social, political and information resources that people need to adapt with, is an obvious fit.

For the MDBs on the other hand, their primary remit is to demonstrate results and draw lessons against building climate resilience. As stated in the recent Aide Memoire:

A key goal of Nepal's SPCR is to provide lessons through learning-by-doing over the next few years that demonstrate modalities for building climate resilience in water resource management and community development planning which can be replicated in other river systems and vulnerable communities (ADB et al. 2010)

Integrating climate change information into existing development strategies as a key aspect of transformational change is relatively straightforward approach that can be assessed and learned from; transforming what is meant by 'business as usual' in the first place, is not.

\section{The power implications of different approaches}

Different conceptualisations of what constitutes climate change resilience and transformational change are closely linked with similarly divergent concepts of what 'national ownership' and a 'country-driven approach' look like. From the government's perspective, if the PPCR is 'country driven', then they should be able to define how 'climate resilience' is interpreted, especially in light of the fact that there is not yet any precedent for PPCR. One of the reasons why the government is so insistent that the NAPA be the basis for PPCR planning and that the PPCR could be used to fund NAPA, is because the NAPA process in Nepal is widely considered to have had a high level of government ownership, has been endorsed by Cabinet and the Prime 
Minster's office, and has been presented by the government as the key national document to:

... provide a basis for the government to guide further climate change governance and manage [climate change] financial resources in a coherent and coordinated manner.

(MOE 2010)

The fact that the government's preference for using PPCR money to fund the NAPA was not accepted (this is because of a different remit of the PPCR compared to NAPA) has resulted in the sense that government ownership is undermined in two ways; first, because the preference of the government is not accepted; and second, because this preference was to build on a 'government led' process.

However, the MDBs face a challenge in enabling the same extent of government ownership over the PPCR as had been afforded in the NAPA. First, because the PPCR does not fall under the UNFCGC; under the UNFCGC it is countries who report to the Conference of the Parties (COP) and the Least Developed Countries Expert Group on their NAPA progress - although implementing agencies are also accountable to demonstrate how they have supported NAPA development. Under the PPCR however, it is the MDBs rather than the countries for whom ultimate accountability rests to demonstrate lessons for climate resilience from the pilots. The MDBs are working on a process for which there is not yet any precedent, they are directly engaging with new administrative structures and ministries that do not have senior coordination experience. At the same time, they need to demonstrate good results, in a timely way. The incentives for strong government ownership are not aligned with those for low fiduciary risk and fast results.

In Nepal, this tension was managed through the use of a consulting team, hired in conjunction with the government, whose remit was drafted in close coordination with the MOE. The consulting team is based in the ministry and was given primary responsibility for the drafting of the SPCR, shifting the power away from the MDBs and towards this SPCR team. As noted by one MDB member:

Other SPCR processes have tended towards standard Bank practices where Banks draft the documents and then go through an iterative process of agreement with governments and consultants. In Nepal the consultants are based in the government, working directly with the government on drafting the documentation... so the process is based on nationally identified priorities that we support. (Interview with MDB representative, November 2010)

This represents a compromise by the MDBs towards greater government ownership of the process. However, from the MOE's perspective, this does not constitute full government ownership. The MOE suggested that it had autonomy particularly over the PPCR funds; and suggested that the consultants were accountable to the MDBs and not to the government. Further, the MOE was not able to direct the PPCR towards funding NAPA - while the remit of the two programmes is different, one government stakeholder suggested, 'If there is no precedent, why can't we make one?' (Interview with MOE, August 2010).

Therefore the interpretations of 'resilience', 'adaptation' and 'transformational change' at the national level and the assumptions and incentives that drive these interpretations have real consequences on the ground for how power is negotiated.

\section{Conclusions}

This article has explored how the objectives of the PPCR of 'climate resilience' and 'transformative change' are being interpreted in Nepal. Neither concepts are consistently defined and are therefore open to interpretation to some degree. This article has shown that the way in which they are taken up by different stakeholders in Nepal reflects both vested interests and also underlying assumptions of the different stakeholder groups. This article has also shown that operationalising these re-negotiated objectives carries implications for both power and resource allocation between different stakeholder groups; specifically, who 'owns' the process, and what 'ownership' actually entails.

One of the key trade-offs identified by this article is that between an emphasis on demonstrating results through the PPCR, versus creating an enabling environment for meaningful 'transformational change'. For the MDBs, the incentives are effectively to demonstrate results of the PPCR specifically - to 'provide lessons 
through learning-by-doing over the next few years that demonstrate modalities for building climate resilience' (ADB et al. 2010.) The need to demonstrate results 'in a few years' is at odds with an interpretation of 'transformational change' that would see longer-term support to stronger governance systems to support 'adaptive management'. The latter involves taking risks, handing over greater responsibility to national governments that may or may not have the capacity to take the agenda forward quickly and effectively.

Thus, incentives are generated to 'climate proof' existing investments, rather than finding new

\section{Note}

* Research for this article was carried out through the Political Economy of Low Carbon Climate Resilient Development project, coordinated by IDS and funded by the UK Department for International Development (DFID). The views expressed here are the views of the authors and do not represent the views or policies of IDS, DFID, or the UK government.

\section{References}

ADB/IFC/World Bank - Government of Nepal (2010) Draft Aide Memoire: Multilateral Development Bank (MDB) Programming Mission for the Pilot Program for Climate Resilience, 10 December 2010

Ayers, J. and Huq, S. (2009) 'Supporting Adaptation through Development: What Role for ODA?', Development Policy Review 27.6: 675-92

Bernstein, S. (2002) 'Liberal Environmentalism and Global Environmental Governance', Global Environmental Politics 2.3: 1-16

Burton, I.; Huq, S.; Lim, B.; Pilifosova, O. and Schipper, L. (2002) 'From Impacts Assessment to Adaptation Priorities: The Shaping of Adaptation Policy', Climate Policy 2: 145-59

Chandani, A. and Siegele, L. (2010) 'Climate Watchlist: Key Issues for Cancun Negotiations', IIED Briefing Papers, November, London: International Institute for Environment and Development

CIF (2009) The Selection of Countries to Participate in the Pilot Program for Climate Resilience (PPCR), January, Washington DC: Climate Investment Funds, www.climateinvestmentfunds.org/cif/ sites/climateinvestmentfunds.org/files/Report \%20of\%20the\%20PPGR\%20EG-Proposal\%20 ways to develop climate resilience. This echoes the conventional framing of adaptation at the global level, that emphasises technocratic solutions and externally driven expert judgement in defining and managing risks; the same ideology that a 'resilience-based' and 'transformative' approach contests. This article therefore suggests that greater attention is needed to understanding the political economy of how these seemingly progressive concepts are negotiated at the national scale, in order to resolve some of the conflicts that arise during this process, and to promote effective and transformative climate resilience on the ground.

1 The premise of liberal environmentalism is that liberalisation of trade and finance is consistent with, and even necessary for, international environmental protection; and that environmental management can be managed through market-based mechanisms (Bernstein 2002: 4).

for\%20Selection\%20of\%20Pilot\%20Programs 2_kd.pdf (accessed 31 January 2011)

CIF (2008) The Pilot Program for Climate Resilience under the Strategic Climate Fund, www.climateinvestmentfunds.org/cif/sites/ climateinvestmentfunds.org/files/SCF_TFG_ Decision_PPGR_Governance_Jan_27_2009.pdf (accessed 7 March 2011)

Clapp, J. and Dauvergne, P. (2005) Paths to a Green World: The Political Economy of the Environment, Cambridge, MA: MIT Press

Dodman, D.; Ayers, J. and Huq, S. (2009) 'Building Resilience', in Worldwatch Institute (ed.), State of the World 2009: Into a Warming World, Washington DC: Worldwatch Institute

IPCG (2007) 'Summary for Policymakers', in M.L. Parry, O.F. Canziani, J.P. Palutikof, P.J. van der Linden and C.E. Hanson (eds), Climate Change 2007: Impacts, Adaptation and Vulnerability. Contribution of Working Group II to the Fourth Assessment Report of the Intergovernmental Panel on Climate Change, Cambridge: Cambridge University Press Klein, R.T.J. (2008) 'Mainstreaming Climate Adaptation into Development Policies and Programmes: A European Perspective', in European Parliament (ed.), Financing Climate 
Change Policies in Developing Countries, Brussels: European Parliament

Mitchell, T.; Anderson, S. and Huq, S. (2008)

Principles for Delivering Adaptation Finance, Brighton: IDS, www.ids.ac.uk/go/idsproject/ principles-for-delivering-adaptation-assistance (accessed 31 January 2011)

MOE (2010) Government of Nepal National Adaptation Programme of Action to Climate Change, Ministry of Environment, Government of Nepal

Müller, B. (2008) International Adaptation Finance: The Need for an Innovative, Strategic Approach, Background Policy Paper for the Climate Strategies Project on Post-2012 Policy Framework: Options for the Tokyo G8 Summit, Oxford: Oxford Institute for Energy Studies

Pelling, M. (2010) Adaptation to Climate Change: From Resilience to Transformation, London: Routledge
Reid, H.; Huq, S. and Murray, L. (2003) Mainstreaming Adaptation to Climate Change in Least Developed Countries, IIED Climate Change Working Paper 1, London: International Institute for Environment and Development Schipper, L. (2007) Climate Change Adaptation and Development: Exploring the Linkages, Tyndall Centre Working Paper Series 107, East Anglia: Tyndall Centre for Climate Change Research Schipper, L. (2006) 'Conceptual History of Adaptation in the UNFCCG Process', RECIEL 15.1: 82-92

SPCR Team (2010) 'Developing Nepal's Strategic Program for Climate Resilience: Prioritisation and Planning Process', draft, Ministry of Environment, Government of Nepal, www.ppcr.gov.np (accessed 15 January 2011) 